\title{
Changing To Removable Casts During The Coronavirus Pandemic - Has It Affected Outcomes For Distal Radius Fractures?
}

\section{Samuel Newman ( $\nabla$ samuelnewman@doctors.org.uk)}

University Hospitals of Morecambe Bay NHS Trust: University Hospitals of Morecambe Bay NHS Foundation Trust https://orcid.org/0000-0002-2178-6378

Amit Singh

University Hospitals of Morecambe Bay NHS Trust: University Hospitals of Morecambe Bay NHS

Foundation Trust

Ashwanth Ramesh

University Hospitals of Morecambe Bay NHS Trust: University Hospitals of Morecambe Bay NHS

Foundation Trust

\section{Ebrahim Mahomed}

University Hospitals of Morecambe Bay NHS Foundation Trust

\section{Timothy Millar}

University Hospitals of Morecambe Bay NHS Trust: University Hospitals of Morecambe Bay NHS Foundation Trust

\section{Research Article}

Keywords: Distal radius fractures, removable cast, coronavirus, COVID-19, pandemic

Posted Date: June 30th, 2021

DOl: https://doi.org/10.21203/rs.3.rs-619698/v1

License: (c) (i) This work is licensed under a Creative Commons Attribution 4.0 International License. Read Full License

Version of Record: A version of this preprint was published at SN Comprehensive Clinical Medicine on October 16th, 2021. See the published version at https://doi.org/10.1007/s42399-021-01066-0. 


\section{Abstract}

Background: BOAST (British Orthopaedic Association Standards for Trauma \& Orthopaedics) guidelines recommended that during the coronavirus pandemic most upper limb fractures should be treated conservatively, and removable casts should be used, where possible. As a result, our district general hospital started using a new soft combination (soft-combi) casting technique for conservative management of distal radius fractures (DRFs) in an attempt to reduce follow-up attendances.

Aims: To assess if radiological outcomes of soft-combi casts are better or worse than previously used rigid casts for DRFs.

Methods: 20 DRFs treated with soft-combi casts were compared with 20 DRFs treated with the old rigid cast types. Radiological parameters were measured pre-manipulation, post-manipulation, at 2-week follow-up, and at final follow-up. Statistical analysis was performed to assess for significant differences seen at follow-up between the groups.

Results: The mean loss of volar angulation seen at 2-week follow-up was 4.9 degrees for the rigid casts vs. 1.5 degrees for the soft-combi casts $(p=0.158)$. The mean loss of radial height after 2 weeks was 0.2 $\mathrm{mm}$ vs $0.5 \mathrm{~mm}(\mathrm{p}=0.675)$, and the mean loss of radial inclination was 2.0 degrees vs 1.0 degrees $(p=0.349)$, respectively.

Conclusion: The soft-combi casts appeared to be equally effective at maintaining the reduction of DRFs compared to their rigid counterparts, as no statistically significant difference was seen in our study. We can be reassured that continued use of these removable casts in the current climate is unlikely to have a detrimental effect on outcomes for DRFs.

\section{Introduction}

Distal radius fractures (DRFs) are a common low-energy injury, often seen in those with osteoporosis following a fall on an outstretched hand. Whilst we have seen a reduction in trauma cases during the coronavirus (COVID-19) pandemic, low energy fragility fractures have continued to make up a sizeable proportion of orthopaedic cases [1]. The number of DRFs occurring in indoor spaces remains constant throughout the year, and as such it has remained a common presentation to hospital throughout the pandemic, despite the restrictions on outdoor activities put in place [2].

Early on in the coronavirus pandemic the British Orthopaedic Association (BOA) released guidelines suggesting that most upper limb fractures could be treated non-operatively, whilst recognising that some patients may need reconstruction further down the line as a result. Additionally, the use of removable casts or splints was advised in an effort to reduce follow-up requirements [3]. These guidelines were created in order to utilise limited National Health Service resources during a time of unprecedented burden. 
There is no literature to date analysing the effect of the use of removable casts on DRF outcomes. It is too soon to assess long-term functional outcome results, but radiological parameters can give us a good indication as to the ability of the new removable casts at preventing fracture displacement and promoting healing. The suitability of these new casts in the conservative management of DRFs can then be compared to the performance of their previous rigid counterparts.

\section{Methods}

\section{Study design}

The district general hospital site of this study started using a soft combination (soft-combi) cast for DRFs on the 27th March 2020. Prior to this it had been trust protocol to use a focused rigid cast for these fractures. We decided to compare the results of the first 20 DRFs - that met the study's inclusion criteria after this date, with the previous 20 legible DRFs to this date. Thus, without adjusting any other factors, we can assume this to be a comparison of the two different cast types.

\section{Exclusion criteria}

All participants of the study must have sustained a DRF that underwent manipulation and casting. Those without the required radiographs - both immediately after manipulation and at 2 weeks follow-up - were excluded, as we could not assess the cast's ability at maintaining the fracture in position.

\section{Data collection}

Participants were identified by going through paper records of the casts applied in the plaster room of the hospital's fracture clinic. Radiographs and patient notes were reviewed retrospectively for those that had had a short arm cast applied to see if they met the study's inclusion criteria. This process continued until 20 legible patients had been identified both prior (going back to 17th December 2019), and after (up to 11th August 2020) the changeover cast date.

For each participant, basic demographics (sex; age; side of injury) were recorded from electronic records. Using the radiology image viewing system PACS we were able to measure the angulation, radial height and radial inclination seen on the radiographs at four specific points in time: pre-manipulation; postmanipulation; at 2-week follow-up; and final follow-up out of cast. Additionally, we measured the cast index $(\mathrm{Cl})$ for the images taken in a complete cast.

\section{Statistics}

Statistics software JASP was used for the analysis of the data.

The difference between the radiographic parameters at 2-week follow-up and post-manipulation were calculated for all patients. The same was then calculated for the difference seen between the final followup and post-manipulation radiographs. Using the Shapiro-Wilk test, the calculated differences for all parameters were shown to be normally distributed in both groups. Therefore, an unpaired T-test was 
performed for each parameter to assess for statistically significant differences between the groups. Welch's T-test was used to compare the difference in heights seen at 2-week follow-up, as Levene's test ( $p$ $=0.046$ ) suggested a violation of the assumption of equal variance. For all other values equality of variance was shown, and Student's t-test could be used.

\section{Results}

\section{Demographics}

The median age at injury of our 40 participants was 68 years. $87.5 \%(35 / 40)$ of the study participants were female. $70 \%(28 / 40)$ of DRFs sustained were left sided, and $45 \%$ (18/40) had intra-articular extension. The mean number of days from sustaining the injury to undergoing a manipulation was 1.5. $15 \%(6 / 40)$ of our study participants ended up undergoing operative intervention due to an unfavourable fracture position during follow-up. 4 underwent open reduction internal fixation (ORIF) whilst 2 underwent percutaneous k-wire fixation.

Table i: Demographics of study participants by cast type

\begin{tabular}{|lll|}
\hline & $\begin{array}{l}\text { Rigid cast group } \\
(\mathbf{n}=\mathbf{2 0})\end{array}$ & $\begin{array}{l}\text { Soft-combi cast group } \\
(\mathbf{n}=\mathbf{2 0})\end{array}$ \\
\hline Median age in years (range) & $67.5(13-81)$ & $69(42-91)$ \\
\hline Gender $(F: M)$ & $17: 3$ & $18: 2$ \\
\hline Side of injury $(L: R)$ & $14: 6$ & $14: 6$ \\
\hline Extra : intra-articular & $10: 10$ & $12: 8$ \\
\hline Mean number of days to manipulation & 2.7 & 0.4 \\
\hline $\begin{array}{l}\text { Operative intervention } \\
\text { (k-wire: ORIF) }\end{array}$ & $2(1: 1)$ & $4(1: 3)$ \\
\hline
\end{tabular}

\section{Radiological parameters}

1 participant from the rigid cast group had no accessible pre-manipulation imaging due to sustaining their injury abroad. The mean degrees of dorsal angulation seen at initial imaging in the rigid and softcombi groups were $17 \& 16$ degrees respectively. The mean radial inclination was 18 and 19 degrees for each group, and the mean radial heights were 8 and $10 \mathrm{~mm}$.

In the radiographs immediately post-manipulation the mean dorsal angulation seen in the rigid group was 3 degrees, compared to 5 degrees in the soft-combi group. The mean radial inclination was 21 and 22 degrees respectively, and the mean radial heights were 10 and $11 \mathrm{~mm}$. 
At 2-week follow-up the mean dorsal angulation for both groups was 8 degrees. The mean radial inclination for rigid casts was 19 degrees, and 22 for soft-combi. Mean radial heights were 10 and $11 \mathrm{~m}$ respectively. The mean $\mathrm{Cl}$ seen in the rigid group was 0.83 ( 1 patient was excluded due to radiographs not adequately including the boundaries of the cast), whereas a mean $\mathrm{Cl}$ of 0.86 was seen with the softcombi casts.

25/40 (13 rigid and 12 soft-combi) participants had follow-up imaging out of the cast. The mean dorsal angulation, radial inclination and radial height at final follow-up for the rigid group were 10 degrees, 19 degrees and $9 \mathrm{~mm}$. The mean values for the soft-combi group were 8 degrees, 21 degrees, and $11 \mathrm{~mm}$ respectively.

Table ii: Mean radiological parameters of study participants by cast type

\begin{tabular}{|lllllll|}
\hline & \multicolumn{2}{l}{ Rigid cast group (means) } & \multicolumn{3}{l|}{ Soft-combi cast group (means) } \\
\hline & $\begin{array}{l}\text { Dorsal } \\
\text { angulation } \\
\text { (deg) }\end{array}$ & $\begin{array}{l}\text { Radial } \\
\text { height } \\
(\mathrm{mm})\end{array}$ & $\begin{array}{l}\text { Radial } \\
\text { inclination } \\
\text { (deg) }\end{array}$ & $\begin{array}{l}\text { Dorsal } \\
\text { angulation } \\
\text { (deg) }\end{array}$ & $\begin{array}{l}\text { Radial } \\
\text { height } \\
(\mathrm{mm})\end{array}$ & $\begin{array}{l}\text { Radial } \\
\text { inclination } \\
\text { (deg) }\end{array}$ \\
$\begin{array}{l}\text { Pre- } \\
\text { manipulation }\end{array}$ & 17 & 8 & 18 & 16 & 10 & 19 \\
\hline $\begin{array}{l}\text { Post- } \\
\text { manipulation }\end{array}$ & 3 & 10 & 21 & 5 & 11 & 22 \\
\hline $\begin{array}{l}\text { 2-week } \\
\text { follow-up }\end{array}$ & 8 & 10 & 19 & 8 & 11 & 22 \\
\hline $\begin{array}{l}\text { Final follow- } \\
\text { up }\end{array}$ & 10 & 9 & 19 & 8 & 11 & 21 \\
\hline
\end{tabular}

\section{Comparison of casts}

The mean loss of angulation seen at 2-week follow-up was 4.9 degrees for the rigid casts vs. 1.5 degrees for the soft-combi casts $(p=0.158)$. The mean loss of radial height after 2 weeks was $0.2 \mathrm{~mm}$ vs $0.5 \mathrm{~mm}$ $(p=0.675)$ for the casts. The mean loss of radial inclination after 2 weeks was 2.0 degrees vs 1.0 degrees $(p=0.349)$.

For those that had final follow-up radiographs, the mean dorsal angulation was 5.6 degrees more than immediately post-manipulation for the rigid cast group, and 2.0 degrees more for the soft-combi casts ( $p$ $=0.33$ ). . The mean radial heights seen at final follow-up for these groups were $0.4 \mathrm{~mm}$ and $0.7 \mathrm{~mm}$ less than the post-manipulation measurements $(p=0.779)$. The mean radial inclinations seen in the two groups had lost 0.7 degrees and 0.8 degrees, respectively, on final imaging $(p=0.461)$.

Table iii: Change in radiological parameters at follow-up by cast type, with T-test $p$-values 


\begin{tabular}{|c|c|c|c|c|}
\hline & & $\begin{array}{l}\text { Rigid cast } \\
\text { group }\end{array}$ & $\begin{array}{l}\text { Soft-combi cast } \\
\text { group }\end{array}$ & $\begin{array}{l}\text { Unpaired T-test } \\
\text { p-value }\end{array}$ \\
\hline \multirow{3}{*}{$\begin{array}{l}\text { At 2-week } \\
\text { follow-up } \\
(n=40)\end{array}$} & $\begin{array}{l}\text { Mean loss of volar } \\
\text { angulation (deg) }\end{array}$ & 4.9 & 1.5 & 0.158 \\
\hline & $\begin{array}{l}\text { Mean loss of radial height } \\
(\mathrm{mm})\end{array}$ & 0.2 & 0.5 & 0.675 \\
\hline & $\begin{array}{l}\text { Mean loss of radial } \\
\text { inclination (deg) }\end{array}$ & 2.0 & 1.0 & 0.349 \\
\hline \multirow{3}{*}{$\begin{array}{l}\text { At final follow- } \\
\text { up } \\
(n=25)\end{array}$} & $\begin{array}{l}\text { Mean loss of volar } \\
\text { angulation (deg) }\end{array}$ & 5.6 & 2.0 & 0.33 \\
\hline & $\begin{array}{l}\text { Mean loss of radial height } \\
(\mathrm{mm})\end{array}$ & 0.4 & 0.7 & 0.779 \\
\hline & $\begin{array}{l}\text { Mean loss of radial } \\
\text { inclination (deg) }\end{array}$ & 0.7 & 0.8 & 0.461 \\
\hline
\end{tabular}

\section{Discussion}

The demographics of our two groups were quite evenly matched. They were of similar ages and gender distribution. The median ages of 67.5 and 69 years are in keeping with fragility fractures (epidemiological studies report the highest incidences of DRFs being in the over $65 \mathrm{~s}$ ). The gender discrepancy seen in our participants matches that seen in previous studies of a nearly 5 times increased risk seen in women: one that is largely attributed to higher rates of female osteoporosis $[4,5]$. The types of DRFs sustained were equally well matched, with the same proportions of left sided injuries between the two groups, and a similar proportion of intra-articular fractures. The preference of this injury for the left wrist is a previously reported phenomenon, as is the predominance of DRFs to remain extra-articular [5].

$10 \%$ of our study participants were eventually treated with operative fixation. Although operative intervention for DRFs seems to be on the increase, rates appear to vary vastly between areas [5]. After BOA guidelines recommended non-operative management of upper limb fractures during the pandemic, we would have expected to see a decrease in DRF fixation. Instead, we saw a two times increase in operative intervention after 27th March 2020 in our two groups (although as we only looked at DRFs that had undergone manipulation this may simply represent an increase in failed attempts at conservative management) [3]. One paper theorised we will see poorer outcomes for DRFs from March 2020 onwards as well as an increase in the number of future corrective surgeries required. This was based on more than $50 \%$ of DRFs managed non-operatively at their trust during the pandemic having at least one radiological parameter that would have previously indicated surgical fixation [6]. This does not take into account, however, that patient factors are widely considered to be the most important markers for whether to intervene surgically, as appose to a unanimous radiological threshold for intervention [7]. In addition, previous research has shown surgical management to improve radiological outcomes only, and not functional outcomes, when compared to conservative management of DRFs [8,9]. Some studies, in fact, 
report that improvements in dorsal tilt with operative, over conservative, management do not extend past the 2-week follow-up. Fracture slippage after this point is greater in those operated on, resulting in no statistical difference in final radiological outcomes between the two management options [10].

The radiological parameters seen on initial presentation were similar for both groups in our study. Manipulation was seen to improve, on average, all radiological parameters, with the greatest improvement being seen in the angulation. Anatomical reduction is a key factor to preventing DRF redisplacement after reduction and cast immobilisation [11].

The soft-combi casts appeared to be more effective at maintaining the reduction than the rigid casts. The average DRF managed with a soft-combi cast allowed the fracture to slip 1.5 degrees dorsally after 2 weeks, and a total of 2 degrees at the completion of treatment. This is compared to a mean of 4.9 degrees at 2 weeks, and 5.6 degrees at final follow-up, seen with the rigid casts. The loss of radial height and inclination, however, was minimal, and fairly consistent, for both cast types. This is despite a mean cast index of 0.83 and 0.86 for the two groups, which are above the $\mathrm{Cl}$ previous studies have deemed acceptable for distal forearm fractures (although it is acknowledged that this may not increase the likelihood of redisplacement) $[11,12]$. These results suggest that the soft-combi cast may be better at maintaining fracture position, although the differences seen were not statistically significant within our study sample. We can, however, at least conclude, that the new soft-combi casts are no worse at preventing fracture displacement than their previous rigid counterparts.

In addition to the radiological outcomes for the soft-combi casts, anecdotally our plaster technicians are reporting reduced rates of patient reattendance for complications. With non-severe skin and cast problems normally affecting around a quarter of fibreglass and hybrid casts, new materials or techniques are needed to prevent re-attendances to hospital [13]. So, with patients experiencing fewer cast complications, and having the ability to safely remove them at home, the soft-combi casts are an ideal cast to use for reducing unnecessary hospital attendances in the current climate. As such, we have shared our casting technique for the soft-combi cast below in figure i.

\section{Study limitations}

- The small size of this study may mean that it does not have enough power to detect statistically significant differences between the two groups.

- Only radiological outcomes, and not functional outcomes, were looked at in this study.

- Cast complications are not always recorded in the notes and so we could not collect any meaningful data regarding this.

- $37.5 \%$ of the participants never had radiographs out of the cast which affects the mean parameters at final follow-up reported in our results.

- Twice as many participants underwent operative fixation in the soft-combi casts, suggesting a more unstable set of DRFs which may affect any comparisons made between the groups. 


\section{Conclusion}

The soft-combi casts appeared to be equally effective at maintaining the reduction of DRFs compared to their rigid counterparts, as no statistically significant differences were seen in our study. As the radiological parameters achieved with soft-combi casts were, at least, equal to those of rigid casts, continued conservative management - chosen in appropriate cases - with these casts can provide other benefits. Further data collection is needed to confirm a reported reduction in hospital visits and cast complications, but logically this can be assumed to be the case. As such, we can be reassured that continued use of these removable casts in the current climate is unlikely to have a detrimental effect on patient outcomes for DRFs, and in fact, may actually be beneficial.

\section{Declarations}

Funding: None

Conflicts of interest: On behalf of all authors, the corresponding author states that there is no conflict of interest.

Ethics approval: All procedures in this retrospective study involving human participants were in accordance with the appropriate ethical standards. The study was registered and approved with the trusts Research \& Development department.

Consent to participate/publish: No formal consent is required for this type of study.

Data transparency: All data supports our published claims.

Code availability: Not applicable

Author's contributions: All authors contributed to the study conception and design. Data collection and analysis was performed by the corresponding author. The first draft of the manuscript was written by the corresponding author, and all other authors were involved in editing the draft. All authors read and approved the final manuscript.

\section{References}

1. Ogliari G, Lunt E, Ong T, Marshall L, Sahota O. The impact of lockdown during the COVID-19 pandemic on osteoporotic fragility fractures: an observational study. Archives of osteoporosis. 2020;15(1):156. https://doi.org/10.1007/s11657-020-00825-1.

2. Øyen J, Rohde GE, Hochberg M, Johnsen V, Haugeberg G. Low-energy distal radius fractures in middle-aged and elderly women-seasonal variations, prevalence of osteoporosis, and associates with fractures. Osteoporosis international: a journal established as result of cooperation between the European Foundation for Osteoporosis the National Osteoporosis Foundation of the USA. 2010;21(7):1247-55. https://doi.org/10.1007/s00198-009-1065-0. 
3. British Orthopaedic Association. (2020) Management of Patients with Urgent Orthopaedic Conditions and Trauma during the Coronavirus Pandemic.https://www.boa.ac.uk/uploads/assets/ee39d8a89457-45339774e973c835246d/COVID-19-BOASTs-Combined-v1FINAL.pdf. accessed 1/12/2020.

4. Nellans KW, Kowalski E, Chung KC. The epidemiology of distal radius fractures. Hand Clin. 2012;28(2):113-25. https://doi.org/10.1016/j.hcl.2012.02.001.

5. Rundgren J, Bojan A, Navarro M, C. et al. Epidemiology, classification, treatment and mortality of distal radius fractures in adults: an observational study of 23,394 fractures from the national Swedish fracture register. BMC Musculoskelet Disord. 2020;21:88. https://doi.org/10.1186/s12891020-3097-8.

6. Baawa-Ameyaw J, Kabariti R, Chandra A, Rhee J. The theoretical impact on corrective upper limb elective services following analysis of distal radius fractures managed nonoperatively during COVID19 pandemic. Bone joint open. 2020;1(10):612-6. https://doi.org/10.1302/2633-1462.110.BJO2020-0126.R1.

7. Johnson N, Leighton P, Distal Radius Fracture Delphi Study Group, Pailthorpe C, Dias J. Defining displacement thresholds for surgical intervention for distal radius fractures - A Delphi study. PloS one. 2019;14(1):e0210462. https://doi.org/10.1371/journal.pone.0210462.

8. Song J, Yu AX, Li ZH. Comparison of conservative and operative treatment for distal radius fracture: a meta-analysis of randomized controlled trials. Int J Clin Exp Med. 2015;8(10):17023-35.

9. Bruyere A, Vernet P, Botero SS, Igeta Y, Diaz H, J. J., \& Liverneaux P. Conservative treatment of distal fractures after the age of 65 : a review of literature. European journal of orthopaedic surgery traumatology: orthopedie traumatologie. 2018;28(8):1469-75. https://doi.org/10.1007/s00590-0182150-x.

10. Hoffmann M, Schroeder M, Kossow K, Gruber-Rathmann M, Ruecker AH. Radiological dorsal tilt analysis of $A O$ type $A, B$, and $C$ fractures of the distal radius treated conservatively or with extra-focal K-wire plus external fixateur. Skeletal radiology. 2012;41(9):1133-9. https://doi.org/10.1007/s00256011-1355-4.

11. Sengab A, Krijnen P, Schipper IB. Risk factors for fracture redisplacement after reduction and cast immobilization of displaced distal radius fractures in children: a meta-analysis. European journal of trauma emergency surgery: official publication of the European Trauma Society. 2020;46(4):789800. https://doi.org/10.1007/s00068-019-01227-w.

12. Kamat AS, Pierse N, Devane P, Mutimer J, Horne G. Redefining the cast index: the optimum technique to reduce redisplacement in pediatric distal forearm fractures. J Pediatr Orthop. 2012;32(8):787-91. https://doi.org/10.1097/BP0.0b013e318272474d.

13. Ekwall A, Carlberg E, Palmberg G, Sloberg R. An audit of complications of fiberglass cast and hybrid cast for fractures of the foot, ankle and forearm in a Swedish emergency department. International journal of orthopaedic trauma nursing. 2018;31:32-4. https://doi.org/10.1016/j.ijotn.2018.05.005.

\section{Figures}




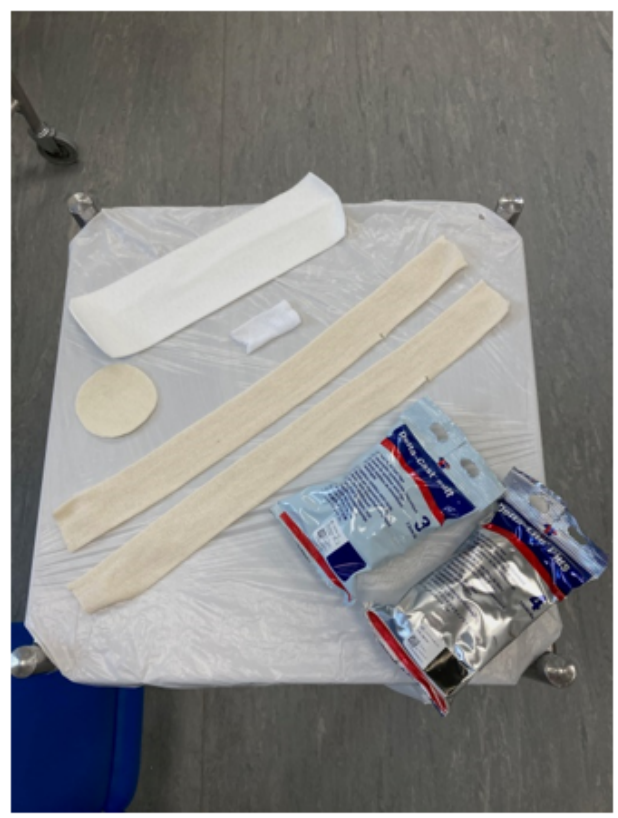

Part a: Cast materials

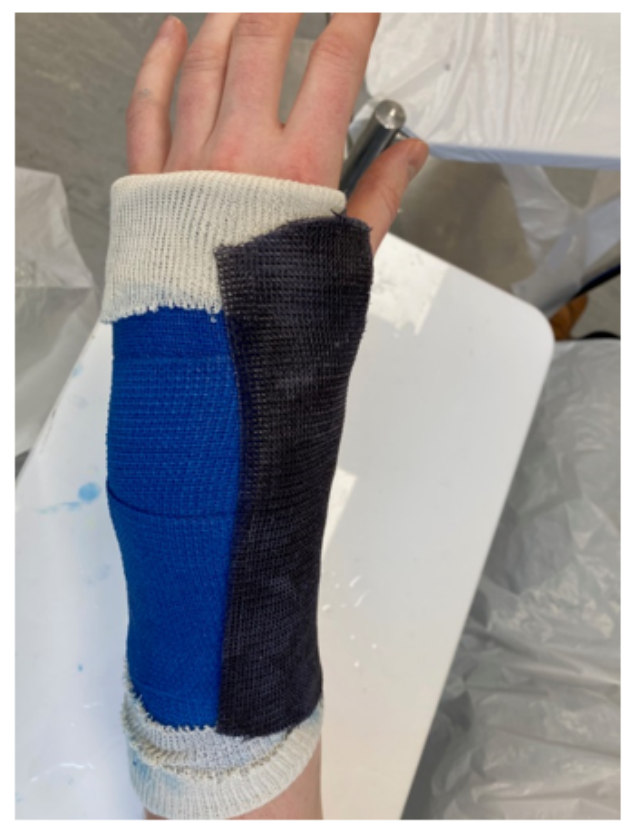

Part c: Polyurethrane resin impregnanted polyester first layer + fibreglass gutter

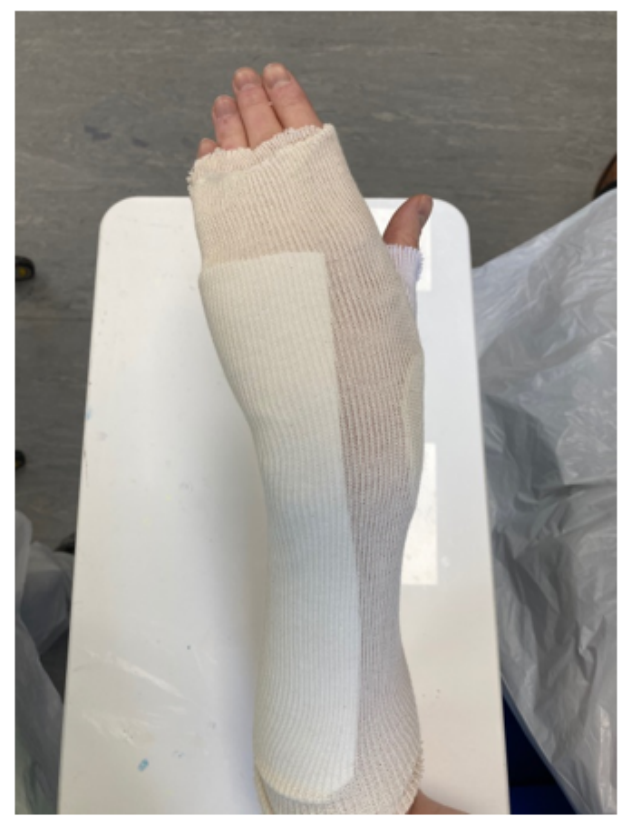

Part b: Stockinette \& padding applied

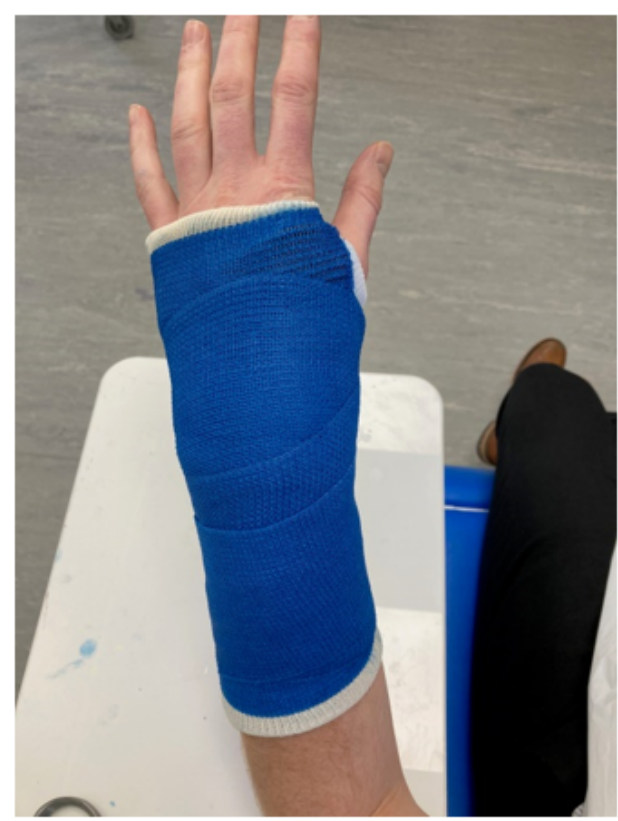

Part d: Final polyurethrane resin impregnated polyester) layer

\section{Figure 1}

Casting technique 